\title{
Social network analysis and organizational control in complex projects: construction of EXPO 2010 in China
}

\author{
YONGKUI LI ${ }^{1}$, YUJIE LU ${ }^{1,2 *}$, YOUNG HOON KWAK ${ }^{3}, \mathrm{YUN} \mathrm{LE}^{1}$ and \\ QINGHUA HE ${ }^{1}$ \\ ${ }^{1}$ School of Economics and Management, Tongii University, Shanghai 200092, China \\ ${ }^{2}$ Department of Civil and Environmental Engineering, University of Maryland, College Park, MD 20743, USA \\ ${ }^{3}$ Department of Decision Sciences, School of Business, The George Washington University, Washington, DC, 200052, USA
}

Received 25 April 2011; accepted 26 June 2011

Social network analysis (SNA) has been widely used to explore the existence and strength of connections among various actors within an organization. Recently, understanding and interpreting social aspects in project organization have gained great interest in project management research. Consequently, there is a need to analyse complex project organization (CPO) by using SNA with increasing numbers of large-scale and complex projects. The goal of this research is to better appreciate the social network relations in a CPO environment and to improve the organizational efficiency and team performance through new organizational control mechanisms (OCMs). This study first discusses a multi-level social network framework with a focus on the CPO where major analytical components of the framework are presented including modelling elements and structures and preferred parameters. Next, social network-oriented OCM and strategies are illustrated and compared with regular organizational controls. To examine the mentioned SNA framework and strategy, this study employs a construction case of EXPO 2010 Shanghai China and analyses the information transmission, role and positional analysis, clique analysis, management power and leadership of the network. The result of the case study provides insightful suggestions for controlling the complex organization, including enhancement of organizational learning ability, standardized working protocols and regulations, and reinforces the management of key information intermediaries, professional requirement for centrality position units and the power shift in some 'special units'. The case also reveals that the informal relations have more significant impacts on the organizational power, leadership and control, especially for complex projects.

Keywords: China 2010 Shanghai EXPO, complex projects, organizational control, social network analysis (SNA).

\section{Background}

With globalization, technological innovation and society evolution, project planning and implementation for human use are becoming larger and complex. Previous studies show that complex projects usually failed due to poor project control (Flyvbjerg et al., 2003; KPMG, 2005; PIPC, 2005; Karlsson and Lukka, 2010) as well as due to human factors (Koerner and Klein, 2008). The complexity from organizational openness, socialization and adaptability brings a new challenge for the project management discipline (Pryke, 2004; Winter et al., 2006; CookeDavies et al., 2008; Van Donk and Molloy, 2008).

Effective organizational control is regarded as a key project management practice for project success, and the lack of it is one of the main causes of failures in complex project management (Whittaker, 1999). Traditionally, project management focus extensively on the use of tools to preplan tasks and develop schedules that are as detailed as possible. However, a project is composed of human, technological and natural actors, each of which is usually not readily controllable by one another. They may be brought under control but

*Author for correspondence. E-mail: lyj0415@gmail.com

The Engineering Project Organization fournal 
may still break loose (Blackburn, 2002). Due to various social characteristics associated with the complex project and its embedded activities, all organizational elements show highly complex and multiple relations, formal and informal. Therefore, the organizational relations of a complex project, normally illustrated as a 'small world network', tend to largely overrun the capability of traditional organizational methodologies and should be solved more properly with the social network-based methodologies (Blackburn, 2002; Chinowsky et al., 2008; Ellmann, 2008).

With the goal of increasing organizational control, this study aims to discuss the following three main questions: (1) How does a social network interpret the complex project organization (CPO) when compared with the traditional organizational approach, such as aspects of organizational institutions, power and relations? (2) How does a social network quantify, measure and analyse key organizational performance factors including network centrality, power, position, clique and cohesion? (3) How does a social network enhance organizational efficiency and project team performance by developing and improving the organizational control mechanisms (OCMs) in accordance with the social network attributes.

To address these problems, this paper first reviews and identifies social network elements, quantified structures and suitable parameters constructing the complex project social network. Then, a framework of OCM for the CPO is established and various strategies are discussed. The EXPO 2010 Shanghai China construction project is further examined as a case study, which covers the establishment of the social network model, data collection, result analysis, as well as the differences between traditional organization and social network perspective, and organizational influence from both formal and informal relations. Moreover, the key factors of the organizational control are also identified. This paper concludes with the improved control principles, methodologies and mechanisms on complex project performance.

\section{Literature review}

\section{CPO and social networks}

Rising from socio-metrics and graph theory, social network analysis (SNA) provides an important method for complex social network and has been widely used in disease transmission, interpersonal relationship, Internet communication and organizational knowledge-sharing areas. Krackhardt and Hason (1993) suggested that social networks provide a better insight into organizational behaviour than a formal structure does. Pryke (2005) argued that SNA has been proposed as an alternative methodology to make project management and government more effective and proposed network density and actor centrality as the appropriate SNA measures to compare the governance of construction projects. Stephan (2005) used a network-centred management perspective rather than a project-centred one to better manage project networks as dynamic organizational forms. Chinowsky et al. (2008) developed a social network model for construction that consists of two basic components: dynamics (experience, reliance, trust and values) and mechanics (communication, information exchange and knowledge exchange). A large variety of research have studied the objectives of complex projects and organizations in the context of social networks such as invisible structures, communication, coordination, coalitions and information dependency to identify their influences on the organizational performance (Pekericli et al., 2003; Pryke, 2005; Ellmann, 2008; Hossain, 2009; Hossain and Wu, 2009).

\section{Organizational Power And Centrality}

Organizational power has a variety of definitions in different research fields (Lukes, 1981; Toffler and Butz, 1990). From the perspective of sociology organization, man's power only exists when he has a relationship with others. Power can be divided into formal authority and informal authority. Power does not exist without the context of an organization; therefore, power is a description of a relationship and not of an attribute of a person (Bushe, 1998). Past studies tried to understand its impact on the organization's health, efficiency and its relation to the productivity and performance (Singh and Eng, 2009). For a project manager, power distance is vital for proposing strategies to manage projects effectively (Tan and Chong, 2003).

In a complex organization, power may rise from multiple sources, including personal aspect (such as experience, seniority and education), formal structure (such as hierarchical and legitimacy), network centrality, possession of information (Pettigrew, 1973), high level of access to various resources (Burt, 1982) and socio-political connections (Hersey et al., 1988; Ibarra, 1993). The key difference between formally and informally derived power is that the latter comes from actors' positions in the actual patterns of interaction that define a social network rather than from their positions in the formally defined vertical and horizontal divisions of labour (Monge and Eisenberg, 1987). Therefore, a person's (or organization's) power can be determined by measuring its relationship location in the context of a project organizational network. If people (or organization) exist as a relationship centre in one organization 
(e.g. information centre or social communication centre), they have the superior power. On the other hand, away from the relationship centre, actors lose power. Chinowsky et al. (2010) stated that power reflects the influence of an individual in the network. The measures of centrality and prominence were designed to identify key individuals in the social network, the potential importance, influence, and prominence (Zemljic and Hlebec, 2005) and network centrality (Wasserman and Faust, 1995).

\section{Group, clique and cohesion}

Group, clique and cohesion are key analytical factors of SNA. Group is concerned with how physical proximity, similarity of beliefs and attitudes, amount of interaction and affective ties are interrelated (Borgatti and Foster, 2003). Clique, also called sub-group, is defined as a small group of people who maintain a tight relationship with each other and gradually form a new sub-group. There are three analytical methods including $\mathrm{n}$-clique, $\mathrm{n}$-clan and n-club based on the reachable and distant calculable principles. As a whole structural indicator for network, clique is used in organization benefit, emotion network, organizational behaviour and conflict management (Luo, 2005). The impacts on cohesion from clique might be either active or passive (Sullivan and Feltz, 2001). Cohesion is defined as 'a dynamic process that is reflected in the tendency for a group to stick together and remain united in the pursuit of its instrumental objectives and/or for the satisfaction of member affective needs' (Carron and Hausenblas, 1998). In the perspective of project organization, cohesion is regarded as close relations with organization communication, coordination, project culture and circumstances, especially in international and cross-culture projects (Schneider, 1995; Mäkilouko, 2004). It has also been regarded as a key variable in models of effective work teams (Carless and De Paola, 2000) and for project success (Gray, 2001; Diallo and Thuillier, 2005).

\section{Organizational control}

The central notion of organizational control assures that behaviours are oriented towards organizational objectives (Etzioni, 1975; Flamholtz et al., 1985). In order to motivate people to behave in ways consistent with organizational goals, control systems must perform the following four related tasks: (1) motivating people to make decisions and take actions; (2) integrating the efforts of several different parts of an organization; (3) providing information about the results of operations and the performance of the actors and (4) facilitating the implementation of strategic plans. Flamholtz (1996) designed a framework of an organizational control system (mechanism) that consists of three parts: a 'core control system', organizational structure and organizational culture.

Nieminen and Lehtonen (2008) concluded that organizational control includes formal and informal control in the form of bureaucratic control, clan control and self-control. Formal control is officially documented and initiated on the level of management, whereas informal control is unwritten and often initiated by employees themselves, though the management actors also use informal forms of control (Jaworski, 1988). Karlsson and Lukka (2010) regarded informal control mechanisms including personal relationship and culture. Simons (1994) found that new managers use formal control systems as a means of implementing strategy. However, informal forms, such as syntonic/harmonious culture, are usually ignored.

In SNA, betweenness is essential for the perceived leadership of project managers because of its potential control of communication (Hossain, 2009). Blackburn (2002) discussed the project manager's location at the centre of the project and the function to keep constantly reinforcing the project organization together.

\section{The social network model for CPO}

\section{Basic elements}

From the perspective of sociological understanding of organization, the CPO covers extensive connotation and denotation that include people, processes, rules, strategies and basic units. The scope of CPO is even fuzzy and difficult to be defined due to its extensive interaction with its surrounding environment. In this study, the social network model of CPO considers the following criteria:

- Scope elements, including project systems and environmental systems, such as external stakeholders.

- Project objectives, including project breakdown structure and work breakdown structure.

- Organizational structures, including formal organizations, such as administrative departments, institutes, officers and informal organizations, such as temporary professional teams, joint conference teams and common interest teams.

- Contract elements, including contract structures and contract relations.

- Separation of duties, including managerial function assignment, working task assignment and working scope relations.

- Information relations, including communication, coordination and knowledge sharing. 
- Dynamics elements, including culture, experience, trust, emotion, brief and value.

- Regime elements, including policy, regulation, instruction and process.

On the basis of SNA theory, the eight criteria mentioned above can be classified into three basic analytical elements in the SNA model as follows ( $\mathrm{Li}$ and $\mathrm{Lu}, 2009$ ):

- Nodes or actors. It could be one person (usually a high-level administrative person or an influential person) or one organization, such as a team, a department, a corporation or a sub-project organization.

- Formal and informal ties. The formal ties include contract relations, outsourcing relations, sales alliance, business groups and strategic alliances. The informal ties indicate information relations, consulting relations, interesting groups, and trust relations. To describe the strength of the relations, both directed ties (such as administrative orders) and degreed ties (such as the intensity of strategic alliance) were discussed in the literature. This research primarily uses the directed and equally degree-tied network (the degree might be equal to 1 or 0 ). The ties together with nodes are basic elements of the social network model. Once the property of nodes changes, the property of ties may change accordingly.

- Environment, including internal and external circumstances, such as procurement methods, policies, regulations, process, cultures and incentives. Environment may affect the numbers and properties of both nodes and ties.

\section{The whole social network model structure and parameters}

The types of organization networks contain the whole network model and personal network model in light of their various research objectives, aims and perspectives. The whole network model focuses on the study of organizational structure, and the personal network model concerns the study of personal value or ego (Liu, 2009). Nevertheless, the concepts of whole network model and personal network model are relative to each other. Generally, the whole network model is widely accepted, but the sub-organization as a personal network model is also regarded as an important 'individual network' that is worthy to be studied. Figure 1 depicts the whole social network structure of CPO.

The organization boundary is fuzzy and unconstant and can be embedded or erased from the model according to different research objectives. As shown in Figure
1, the subsystem may cover different participants including owners, designers, contractors, suppliers, stakeholders and authorities. On the other hand, the model can also be established in accordance with specific research needs, such as the administrative order relation network model, information communication network model and decision-making relation network model. The network model regards all stakeholders either as a whole network model or different personal network models for the purpose of improving organizational performance and achieving a successful project outcome.

In order to vividly illustrate the $\mathrm{CPO}$ and design an effective organizational control in quantitative modelling, various measures and related parameters are discussed. Based on the organizational control and characteristics of SNA, there are two major variables to describe the social network: the controlled objects and their properties, which can be measured by four indicators: network density, clique, centrality and similar structure (Hanneman and Riddle, 2005). Used notations and variable description are given in Table 1.

\section{OCM design}

The aim of organizational control is to guide the organizational behaviours aligning with organizational goals and strategies (Flamholtz et al., 1985; Flamholtz, 1996; Nieminen and Lehtonen, 2008; Seeck and Kantola, 2009). Ouchi (1979) suggested three types of OCMs including market control, bureaucracy control and clan control models. Therefore, with regard to $\mathrm{CPO}$, this study has considered that a successful project control extensively depends on effective organizational controls, especially on identifying, analysing, managing and controlling the key organizational units and key connections.

After establishing and analysing the social network model, the key performance of organizational control becomes clearer and more solvable. In detail, definitions of power and actors make the key priorities of OCM highlighted and simplified. Analysis of clique can make the whole organization under a more controllable status. Study of similar structure actors can make the job position and work process clearer and more responsible. The function and value of social network in OCM are given in Table 2.

\section{Case study: 2010 Shanghai EXPO construction management organizations}

In order to examine the social network model and to investigate the organizational controls in a complex environment, this study has employed a construction 


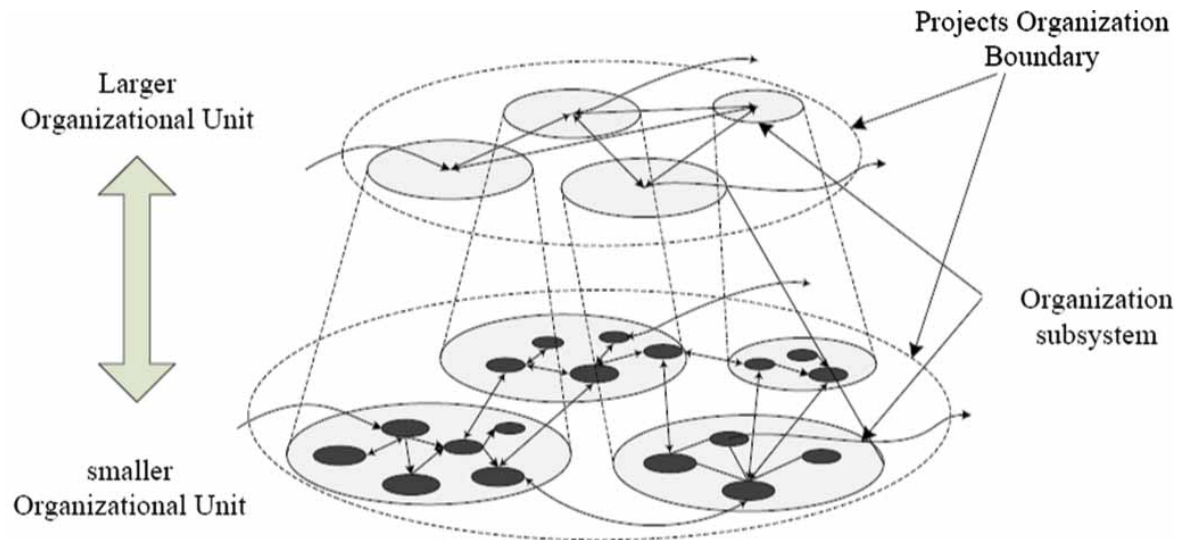

Figure 1 The whole social network structure of CPO

case in China. The current fundamental reality in China is that most large and complex construction projects are invested and led by the Chinese government. These projects adopt 'headquarter' (otherwise called 'Zhihuibu' in Chinese) as a major organizational model that has an intensive administrative background. This organizational model is proven to considerably improve the entire project organizational efficiency and drive the project forward to meet the scheduled cost and time. However, problems exist in this traditional organizational model, such as focusing on short-term results and being costly to manage. In addition, such governmental construction projects have high uncertainty resulting from diverse political struggles where the project is left without necessary political support and legitimacy (Arnaboldi et al., 2004). Therefore, it is worthy to reconsider the organizational controls in complex realities of construction projects in China, since they largely impact the typical organizational model and even the project success.

Table 1 Notations and parameters used in SNA

\begin{tabular}{|c|c|c|}
\hline Variable & Notation & Description \\
\hline $\begin{array}{l}\text { Network } \\
\text { density }\end{array}$ & $\Delta$ & It measures the degree of ties among one group. \\
\hline \multirow[t]{2}{*}{ Clique } & n-cliques & $\begin{array}{l}\text { It regulates that the distance between any two persons in this clique is shorter or equal to } \\
\mathrm{n},[d(i, j) \leq n] \text {. }\end{array}$ \\
\hline & E-I index & $\begin{array}{l}\text { It gauges the degree of the clique in a whole organization. The high E-I index stands for a } \\
\text { serious clique problem in the overall organization and may negatively impact the } \\
\text { organizational control. }\end{array}$ \\
\hline \multirow[t]{3}{*}{ Centrality } & $C_{D}(\imath)$ and $C_{D}$ & $\begin{array}{l}\text { The large value of } C_{D}(i) \text { indicates the more power owned by the node } i \text {. The large value of } \\
C_{D} \text { indicates the high concentration of power in an organization that is easier to control. }\end{array}$ \\
\hline & $C_{B}(i)$ and $C_{B}$ & $\begin{array}{l}\text { The node with a lower } C_{B}(\imath) \text { indicates an important intermediary in the network, and this } \\
\text { node has great influence over what flows in the whole network. The higher the } C_{B} \text { is, the } \\
\text { more significant the intermediary becomes as the organization divides into several small } \\
\text { sub-organizations and might negatively impact the organizational control due to possible } \\
\text { manipulation of information and resources. } \\
\qquad[n\end{array}$ \\
\hline & $C_{C}(\imath)$ and $C_{C}$ & $\begin{array}{l}C_{C}(i)=\left\lfloor\sum_{j=1}^{n} d_{i j}\right\rfloor \text {, here } d_{i j} \text { is defined as the distance between the node } \mathrm{i} \text { and node } \mathrm{j} \text {. It also } \\
\text { represents how much node } \mathrm{i} \text { is controlled or impacted by node } \mathrm{j} . C_{C} \text { is highly similar to } \\
C_{D} \text {, and it needs a strict requirement for the network, and therefore, } C_{C} \text { is seldom used in } \\
\text { the research. }\end{array}$ \\
\hline $\begin{array}{l}\text { Similar } \\
\text { structure }\end{array}$ & $\begin{array}{l}\text { Euclidean distance } \\
\quad\left(d_{i j}\right)\end{array}$ & The roles and positions are much similar if $d_{i j}$ approaches zero. \\
\hline
\end{tabular}


Table 2 SNA and organizational control

\begin{tabular}{|c|c|c|c|}
\hline No. & $\begin{array}{l}\text { Key issues in organizational } \\
\text { control }\end{array}$ & SNA considerations & Rethink the organizational control \\
\hline 1 & Organizational cohesion & Network density & $\begin{array}{l}\text { Evaluation and improvement of organization cohesion } \\
\text { oriented by network density }\end{array}$ \\
\hline 2 & Organizational sub-groups & Clique analysis & Utilization or improvement of cliques \\
\hline 3 & Organizational key persons & Personal centrality & Focusing on and monitoring of key persons \\
\hline 4 & $\begin{array}{l}\text { Organizational authority } \\
\text { distribution }\end{array}$ & $\begin{array}{l}\text { Centrality, centralization and } \\
\text { power }\end{array}$ & Reasonable authority assignment and separation \\
\hline 5 & $\begin{array}{l}\text { Organizational information } \\
\text { communication }\end{array}$ & $\begin{array}{l}\text { Network density, information } \\
\text { path }\end{array}$ & Information control \\
\hline 6 & $\begin{array}{l}\text { Information aggregation and } \\
\text { integration }\end{array}$ & $\begin{array}{l}\text { Network structure holes, } \\
\text { bridges, 'stars', etc. }\end{array}$ & Information control \\
\hline 7 & Properties of decision-makers & Power, order paths & $\begin{array}{l}\text { Sufficiency, efficiency and timeliness of decision- } \\
\text { making }\end{array}$ \\
\hline 8 & Order paths & Distance, reachable & Scope and timeliness of the order \\
\hline 9 & Member/team abilities & $\begin{array}{l}\text { Compatibility of the nodes } \\
\text { (actors) }\end{array}$ & Compatibility between the task and the ability \\
\hline 10 & $\begin{array}{l}\text { Position and process } \\
\text { standardization }\end{array}$ & Role and positional analysis & Position design and regime design \\
\hline 11 & Impacts of informal relations & $\begin{array}{l}\text { Sensitive analysis of changing } \\
\text { relations }\end{array}$ & Attention on informal relation impacts \\
\hline 12 & $\begin{array}{l}\text { Impacts of external } \\
\text { environment }\end{array}$ & $\begin{array}{l}\text { Sensitive analysis of loading } \\
\text { relations }\end{array}$ & Attention on external relation impacts \\
\hline
\end{tabular}

\section{Case background}

EXPO 2010 Shanghai China (EXPO 2010) is the largest construction site in EXPO history, which covers $6.68 \mathrm{~km}^{2}$ planned areas and over 2 million square metres of building areas. There are 100 different construction projects, 300 official construction companies, 20,000 construction workers and over 20 billion RMB investments. EXPO 2010 construction organization is, therefore, highly complex since it involves single-project organizations, multiple-project organizations, governmental representative organizations and cross-functional organizations. According to 'EXPO 2010 construction project management outline', the simplified EXPO 2010 construction organizational structure is depicted in Figure 2.

EXPO 2010 sets up a temporary Construction Headquarters Office (CHO) to represent the government. The CHO is composed by construction managers and engineers, who may come from government departments or on secondment from construction companies and professional consulting companies. $\mathrm{CHO}$ uses strong matrix organizational structure, consisting of 12 functional departments and 12 project departments (Figure 2). The functional departments are responsible for the overall regulation, coordination and control, such as safety management department and equipment and materials department. The project departments are in charge of the engineering implementation and on-site coordination and they apply flexible organizational models due to different project sizes. Figure 2 shows different project departments, such as the China pavilion project department and art performance centre project department.

\section{Data collection}

The more than hundreds of units and organizations involved in the EXPO 2010 construction make the organizational relations complicated. Moreover, due to the fact that most relations exist as informal links, it is impossible and unrealistic to fully simulate and map the organization by using the entire organizational units and relations. This case study has selected research multiple objectives to study the SNA model applications in organizational controls, including 49 organizational units, 5 major sub-projects in eastern construction areas and $8 \mathrm{CHO}$ departments.

By considering the information accessibility, effectiveness and sufficiency, this case has examined the following types of organizational relations: consortium relations, strategy alliance relations, the project (subproject) team relations, contractor and subcontractor 


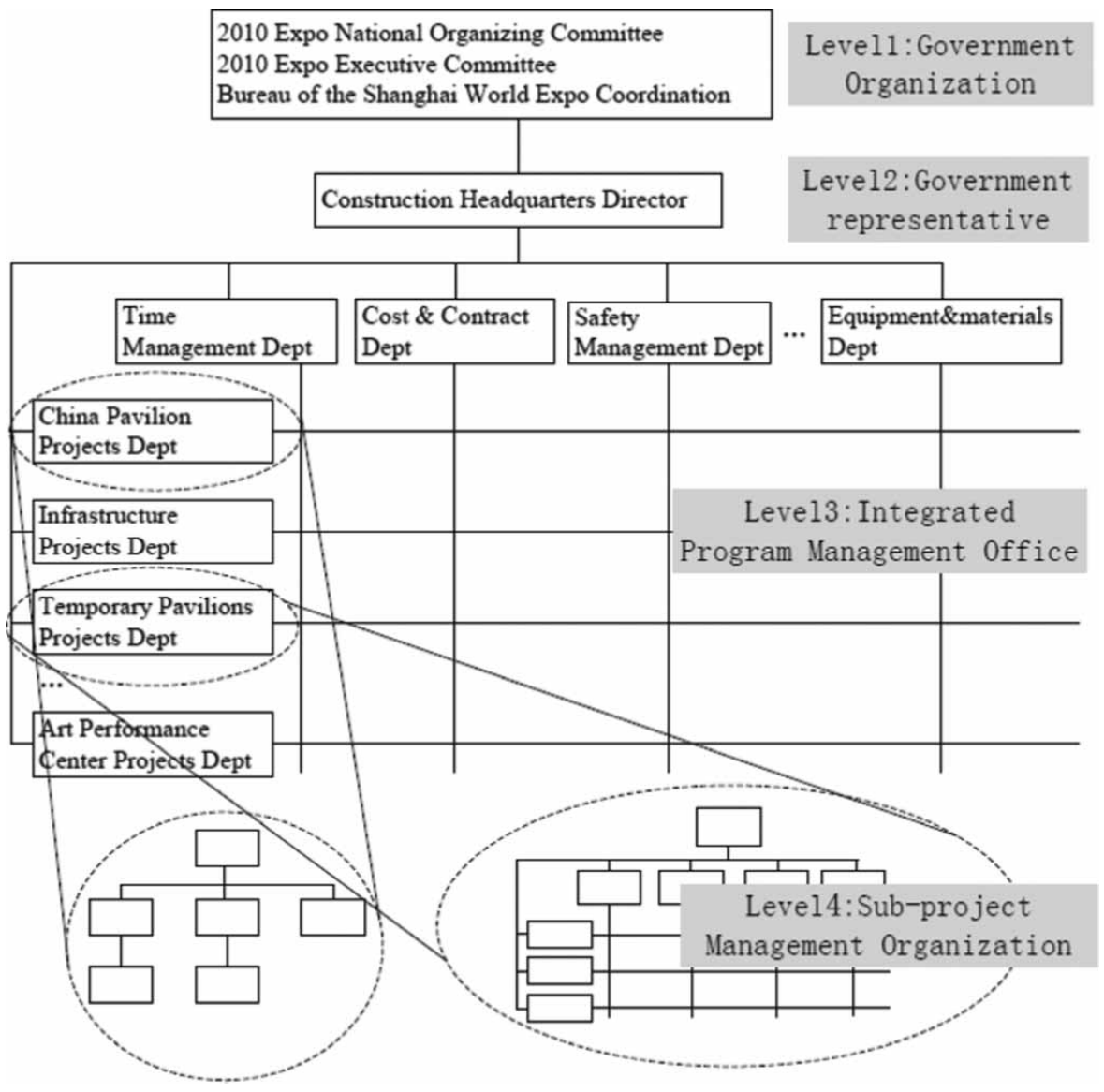

Figure 22010 EXPO construction organizational structure

relations, working staff relations, official organization orders, administrative regulations and other informal relations. In order to avoid the risk of information distortion, the case information has been directly gathered from project regime and documents, administrative regulation, staff information, contract relationship, regular and joint-meeting information, and special topic workshop relations. Primary data collection approaches and information resources are as follows:

- The organizational relations of the $\mathrm{CHO}$ and related departments come from 'EXPO 2010 construction project management outline (2008/2009 editions)'.

- Relations and connections of key management of $\mathrm{CHO}$ come from administrative secondment letters.

- Contractual relations come from 'EXPO construction Project Management Information System platform' and 'EXPO construction archives: contract management series'.

- Organizational coordination and information communication relations come from 'EXPO construction archives: coordination management series, integrated management series', regular meeting minutes and memoranda.

- All other professional and functional information sources, such as material and equipment management, safety management, quality assurance and quality control, come from 'EXPO 2010 construction project management outline (2008/2009 editions)', 43 administrative regulations and 42 working procedures.

\section{SNA model establishment}

The SNA model adopts directed and equally degreetied network, assuming that the relation of two organizations is set to ' 1 ' if any existing relations refer to the following four types: organization, order, information and coordination. Otherwise, the relation is equal to ' 0 '. In the network, each node refers to one organization or sub-organization. The models can be established from two aspects: order-oriented network model and integrated social network model. After inputing all the 


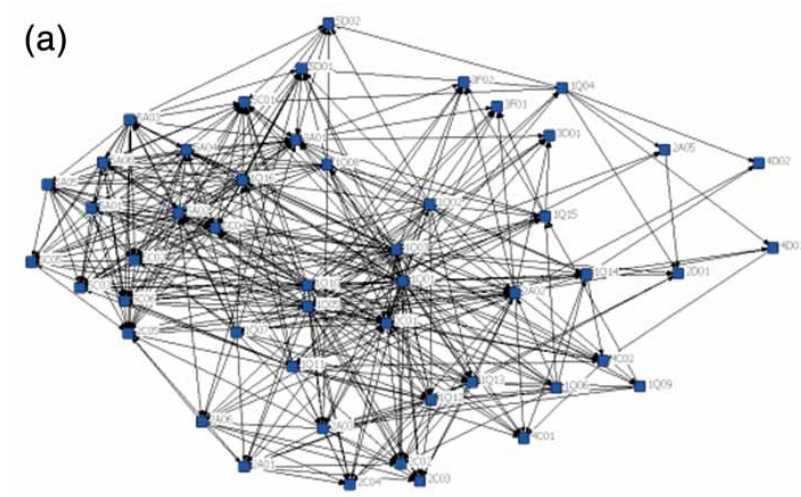

(b)

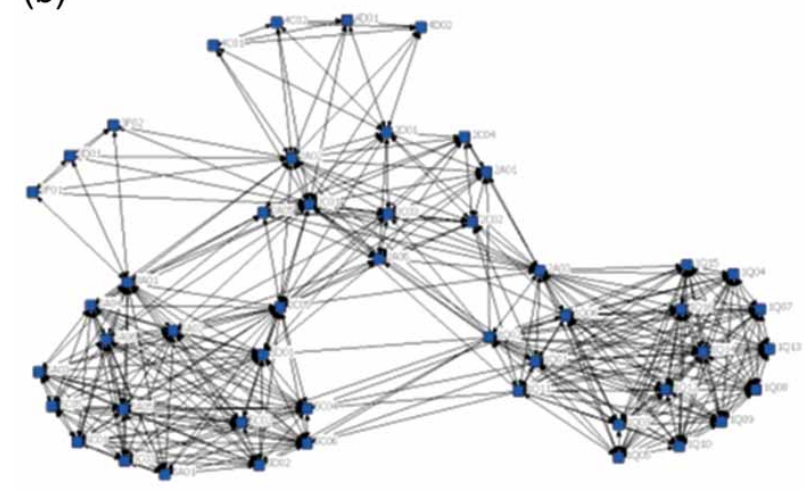

Figure 3 Two types of organization social networks of Shanghai EXPO construction. (a) The order-oriented network model. (b) The integrated social network model

information of the nodes and ties into the UCINET, which is a comprehensive SNA package, two types of models are obtained, which are presented in Figure 3.

Figure 3(a) and (b) shows significantly different network characteristics. In Figure 3(a), the overall network out-degree centralization and in-degree centralization are $64.757 \%$ and $22.222 \%$, respectively, which have wide differences. The reason is that EXPO 2010 construction adopts a flat organizational structure model, and units may receive multiple orders from cross-departments. Strictly speaking, order-oriented relation model (as shown in Figure 3(a)) is not a formal social network graph since orders are transmitted in one direction. However, Figure 3(b) considers all related factors comprehensively and, therefore, has more typical social network characteristics and more values to analyse.

\section{Result and discussion}

Based on the above algorithm, we have inputted all the data and calculated the integrated social network model by using UCINET software. The result of the whole
Table 3 SNA results of EXPO 2010 construction organization

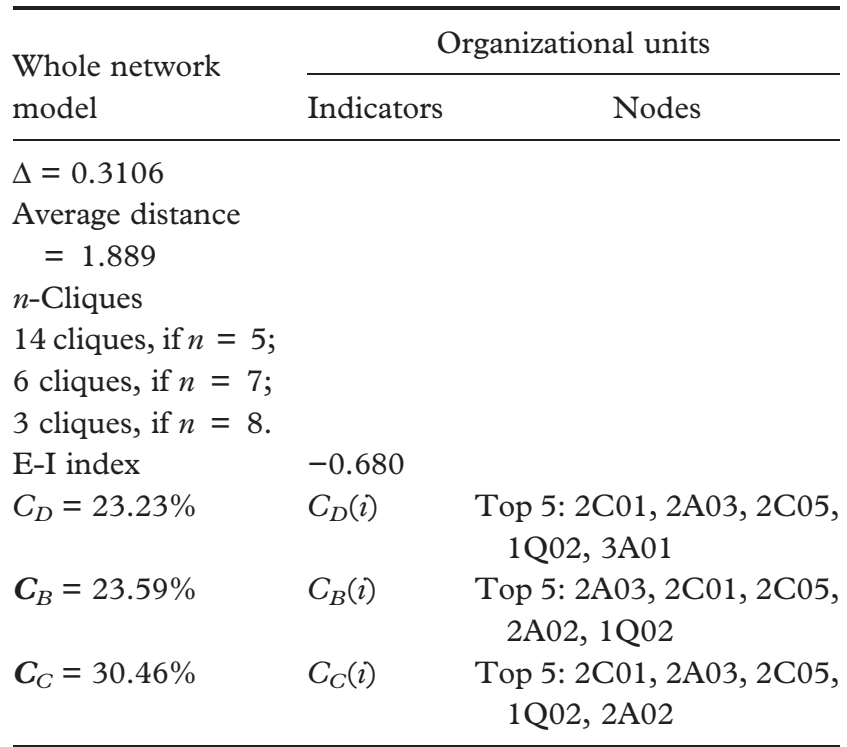

Note: (1) The abbreviations use a universal numbering rule in the entire study. The first number in the abbreviation means subprojects, that is, 1 is projects of $\mathrm{CHO}$ and 2 is pavilions and temporary facilities in Pudong area. The second letter in the abbreviation means sub-organizations in one project, that is, $\mathrm{Q}$ is $\mathrm{CHO}$ and $\mathrm{C}$ is contractors. The third and fourth numbers are running numbers to indicate a specific unit or person in a suborganization, that is, $1 \mathrm{Q} 01$ is the director in $\mathrm{CHO}$ and $1 \mathrm{Q} 04$ is a manager of technics in CHO. (2) The full notations of these abbreviations are given in Appendix 1.

network model is given in Table 3 and insightful conclusions are drawn from the analysis.

The whole organization has low network density and centralization, meaning that the relations crossing subprojects are loose and relatively simple. This situation can benefit the organizational control but may jeopardize the cross-organization learning ability and information communication. Most characteristics of this network are similar to those of the strong matrix organization.

The organization is a highly efficient information transfer network, since the average transitive tie is lower than 2, and the maximum tie is equal to 3. For $1 \mathrm{Q} 02$, the maximum tie to any node in the organization is 2 , which means that $1 \mathrm{Q} 02$ has strongly transitive ties and short order paths.

This study has also conducted the role and positional analysis by using Euclidean distance, and the result is shown in Figure 4. There are considerable discrepancies for roles and positions in different organizations, but not in the same organization. One reason may arise from the project's temporal and complex characteristics. These considerable varieties also call for the requirement and necessity to incorporate 


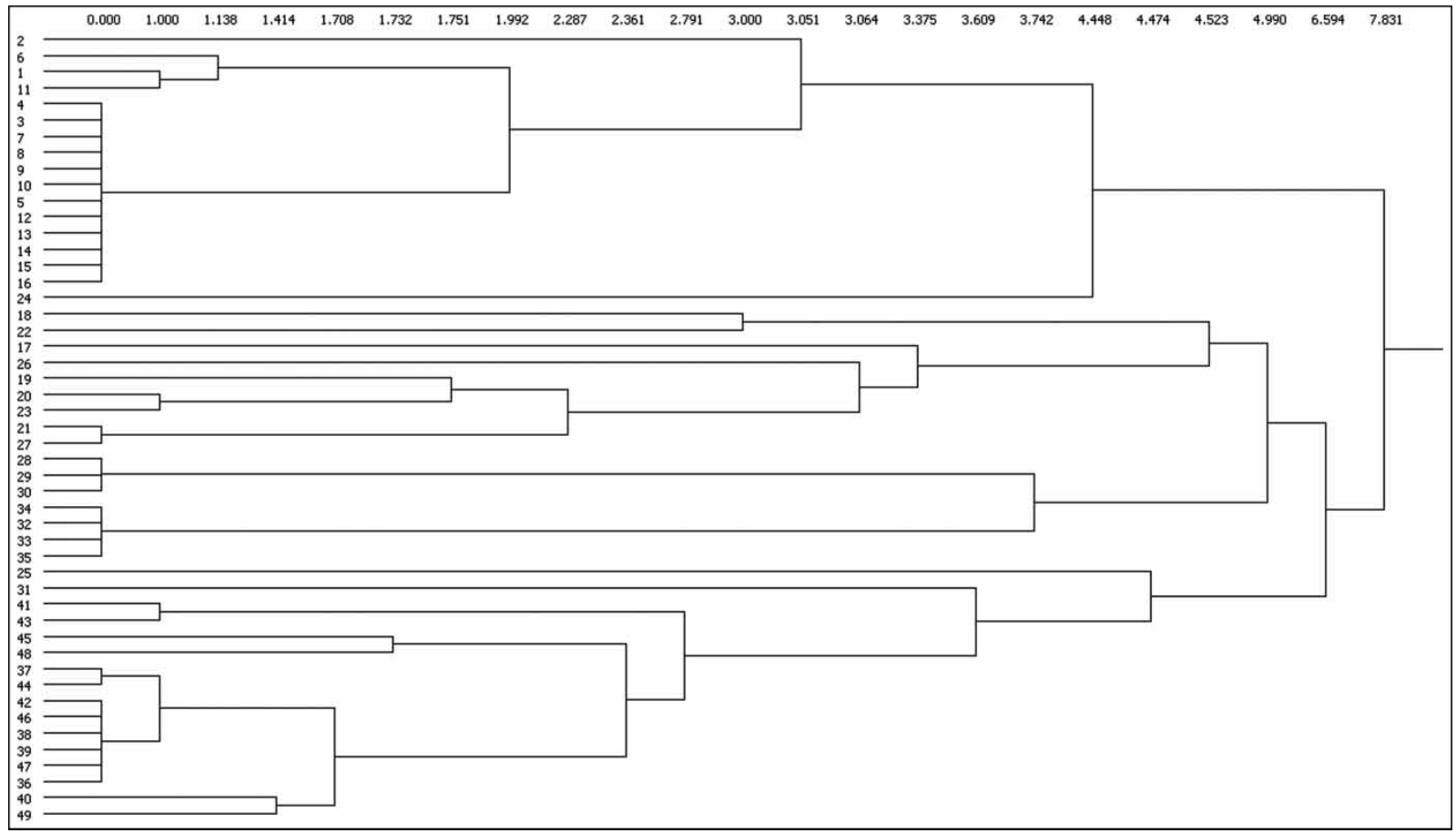

Figure 4 Histogram of role and positional analysis

standardization, procedures and institutionalization into project management practices to improve work efficiency.

The value of E-I index $(-0.680)$ is low in this organization, which means that every clique has a clear boundary, and the members of each clique maintain a tight relationship with each other. For example, when the number of sub-groups is 7 , there are 6 cliques (see Table 4) and following observations can be made:

- Clique 1 (pavilions and temporary facilities in Pudong area), clique $5(\mathrm{CHO})$ and clique 6 (roads and municipal projects in Pudong area) have similar properties and belong to the same sub-project, suggesting that strong relationships exist inside this sub-project.

- Most nodes of clique 3 come from clique 1 and 1Q02, and most nodes of clique 4 come from clique 6 and 2C01. Results indicate that these nodes that moved from an old clique to a new clique would still maintain a close relationship with the previous one, which potentially increased the relationship of the two cliques. These intermediate nodes are identified as key participants, such as project management firms, design firms and construction general contractors. Similarly, 1Q02 (deputy direct of $\mathrm{CHO}$ ) is deeply involved with clique 3, and 2C01 (a large state-owned general contractor) intensively participated in the activities of clique 4 .

- Clique 2 includes all nodes that participated in this sub-project as well as the largest design firm (2D01) and largest general contractor (2C01) in the EXPO project, since clique 2 (China pavilion) has built the most symbolic landmark in the whole EXPO site. The relations in this clique maintained very tight connections. In addition, Chinese state-owned companies (i.e. 2D01 and 2C01) participated and led to the symbolic project on a large scale.

- The units having multiple relations for two or three cliques, such as the nodes that have been underlined in Table 4, may act as important intermediaries in the cross-network. For instance, 2C01 and 2A03 are general contractors and project management firms, respectively, playing a great role in communicating with other involved units, even more frequently than $\mathrm{CHO}$ does. The extensive communication and coordination functions also warn that more management and control techniques should be implemented to monitor and prevent these key units from abusing power. In each single clique, key contracts within the clique may act as intermediaries as well. To improve the efficiency of management and information communication, reinforced governance and effective 
control should be attained to these underlined nodes.

There are four nodes that appear most frequently and have relatively high centrality: 2C01, 1Q02, $2 \mathrm{C} 05$ and 2A02. They are on behalf of the largest contractors, CHO (government), key contractors, and key consulting firms, respectively. This result exactly matches the following issues, such as characteristics of EXPO $2010 \mathrm{CHO}$ and general construction organizational model (i.e. 'Trinitarian' construction system of ' $\mathrm{CHO}$, general contractor and project management'), characteristics of large and complex construction projects and the principle of 'making use of consortiums advantage'. The result also implies that each organization or person that is located in the centrality position is required to have a competitive ability to manage such CPO.

Attention should also be paid to 'special nodes' that have higher centrality and power in the network analysis but have lower authority in the conventional organizational structure analysis. For example, the node of 2C01 extensively overruns its administrative power and leadership in social network rather than its supposed function in the organizational structure. This can be explained by the fact that $2 \mathrm{C} 01$ is the largest government-owned general contractor and has considerable connections with most of the construction participants both formally and informally. Therefore, more organizational control should be considered and redesigned to this unit, in case it monopolizes information or other resources leading to the failure of projects.

\section{Redesigning the OCM}

The results and discussion presented above provide a quantitative insight to design a highly efficient OCM. First, organizational structures have different impacts on the organizational relationship, and the matrix structure can effectively reduce the organizational complexity. Second, both formal relations and informal relations simultaneously exist in the complex organization. The effects of informal relations and resulting cliques could be either positive or negative for the organizational control. Hence, a sound OCM should both expand the positive effect (for instance, establishing a healthy organizational culture) and avoid the negative effect through rigid controls and regulations. Third, a comprehensive control over the entire project organization as well as specific key actors (i.e. nodes with a higher level of $C_{D}, C_{B}$ and $C_{C}$ ) should be taken carefully. Last but not least, the positions and roles vary considerably in CPOs and need more sophisticated management toolkits and standardized-, proceduralized- and institutionalized-control approaches.

Based on the above analysis and properties of the EXPO 2010 construction project, the final organizational control construction is summarized in Table 5 and categorized into formal controls and informal controls. Formal controls aim to build a competitive project management skills and controllable management environment and put more emphasis on the organizational structure model, law requirement, institutional design, target control and professional team management. However, for a complex project, due to the complexity of organizational structures and relationship, as well as emerging connections of informal and implicit relations, the goals of project participants are diversified and may conflict with each other. In order to align different sub-organizational goals together, it is necessary to encourage the self-control mechanisms and reduce the risks of key actors' power and cliques' behaviour. Ultimately, educating and establishing a positive project value system for all organizational units and shaping an optimal project culture are testified as effective approaches from the case study. These control strategies also match the properties of organizational networks and ensure the success of the project. In the case of EXPO 2010 construction, these organizational strategies and mechanisms have a key role in the construction project success and support the project to achieve multiple goals including schedule control, cost control, quality control, safety control, environmental

Table 4 Six cliques and contained components

\begin{tabular}{|c|c|}
\hline No. & Components (network nodes) \\
\hline 1 & 2D012C01 2C02 2A01 2C03 2A02 2C04 2A03 2C05 2A05 2A06 \\
\hline 2 & $\overline{2 \mathrm{D} 012 \mathrm{C} 01} 2 \mathrm{~A} 024 \mathrm{D} 014 \mathrm{D} 024 \mathrm{C} 014 \mathrm{C} 02 \overline{ }$ \\
\hline 3 & $1 \mathrm{Q} 022 \mathrm{C} 012 \mathrm{~A} 012 \mathrm{C} 032 \mathrm{~A} 022 \mathrm{~A} 032 \mathrm{~A} 06$ \\
\hline 4 & 2C01 2C05 3A01 5A02 5D01 5A04 5A06 \\
\hline 5 & 1Q01 1Q02 1Q03 1Q04 1Q05 1Q06 1Q07 1Q08 1Q09 1Q10 1Q11 1Q12 1Q13 1Q14 1Q15 1Q16 2A03 \\
\hline 6 & 2C05 3A01 5C01 5C02 5A01 5C03 5C04 5A02 5A03 5D01 5D02 5A04 5C05 5A05 5A06 5C06 \\
\hline
\end{tabular}

Note: Notations are explained in Appendix 1. 
Table 5 Redesign OCMs of Shanghai EXPO 2010 construction

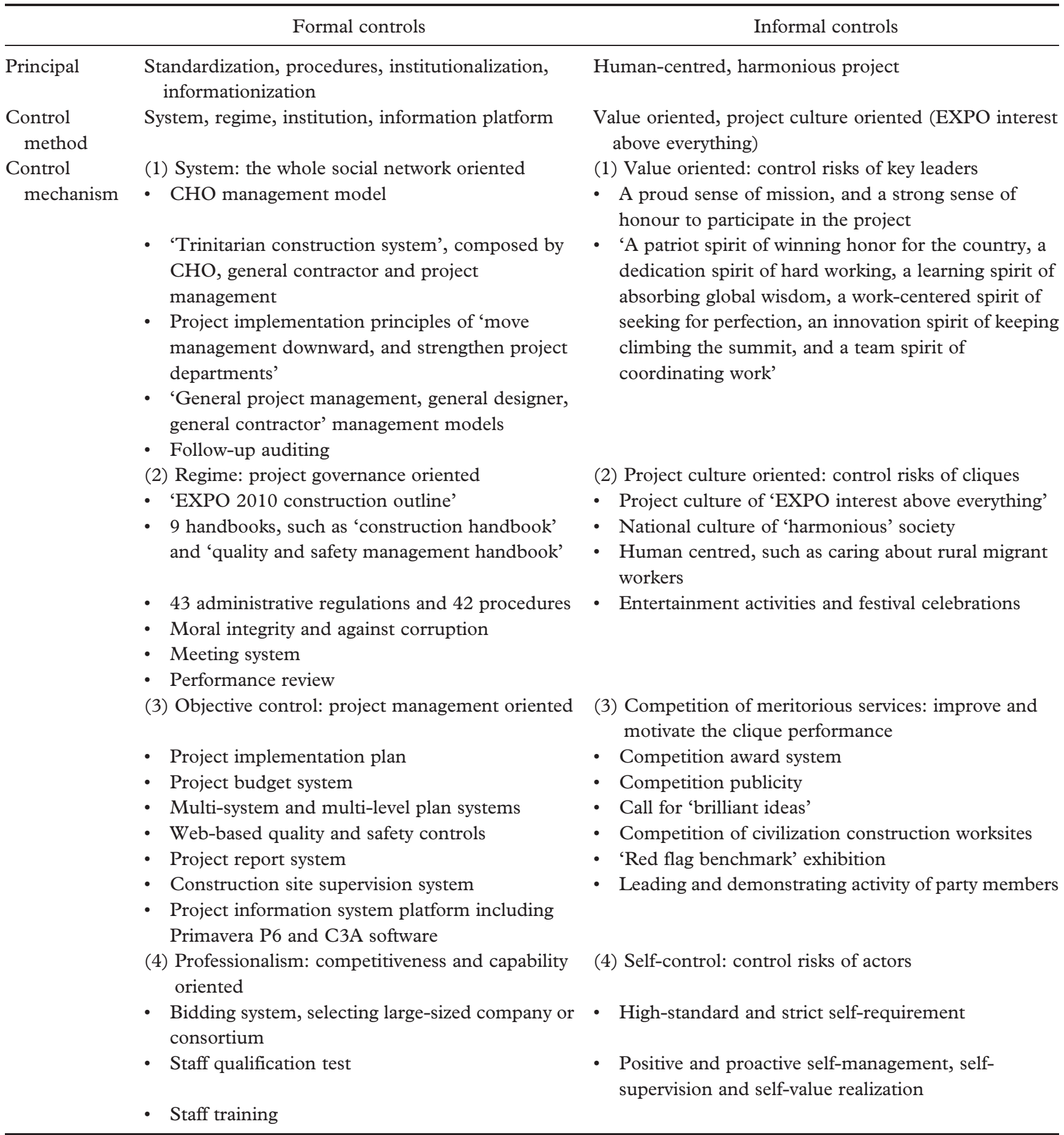

and health control, team training, anti-corruption and local community involvement. After the EXPO 2010 ended, the national post-audit and post-evaluation results earned high scores for all aspects, especially on the project performance and anti-corruption, in which the optimized organizational control was regarded as the key factor.

\section{Conclusions}

Due to the absence of applicable theory, both academics and practitioners mainly focus on the formal organization research in complex projects for a long term. The organization management is inclined on using tool-oriented 'hard' management, such as project 
objective control and performance control, or using strict administrative management, such as regime system control. However, these conventional methodologies hardly match the complex project characters and ignore the influences from 'soft' perspective of organization, such as the organizational openness, social characters and informal organizations.

This paper, based on the SNA theory and a quantitative case analysis, has put forward a social perspective to reconsider the organizational controls in a CPO. By fully considering both formal organization and informal organization aspects, analysing various social network elements and establishing the whole social network model for the complex projects, the value of organizational controls and social network-oriented OCMs and strategies has been discussed. Then, a real case study of EXPO 2010 construction organization has been used to validate the proposed social network model and the organizational control methods. The computational results have provided six intuitive observations and a set of newly designed OCMs and strategies to this project. In summary, there are four conclusions which are deviant from the previous literature and meaningful for the complex organizations in the future:

- Large-scale construction project results in a complex organization network in which the composition and relationship are complicated, multiple cliques and sub-groups emerge and the true function of organizational units may mismatch with the designated formal position in an organizational structure. Therefore, effective analysis, management and control of the complex organization lead to the project success.

- SNA provides a powerful methodology and tool to study the CPO. The measures of network density, clique, centrality, and similar structure can help to identify the key actors or cliques in a complex organization and to set a specific control strategy.

- Control mechanisms encompass two aspects: formal controls and informal controls. Formal controls form the basis of project management competencies and insist on institutional systems, organizational structures, management units, professional qualifications, regimes and tools. Informal controls emphasize 'soft' strategies in personal value systems and project cultures in order to manage the risks of key actors' or cliques' behaviours. By doing this, each small organization can be self-controlled, which ultimately brings the entire project under control.

- $\mathrm{CHO}$ is a unique and specific organizational structure model for Chinese large-scale construction projects. This model brings a variety of benefits, including reinforcement of the general controllable capability and coordination for organizations, effectively manages both the formal and informal relations, efficiently transforms the information in a short path and ensures that the project goals and key milestones are accomplished. However, there are few empirical studies of the feasibility and effectiveness of this model used in other countries besides China, and future work on the application for multiple locations is appreciated.

SNA has shown unique advantages and competitiveness in many sociology and organization research. As a new method for complex organization systems, SNA also provides a new research perspective and shows potential values in the future research, such as organizational behaviours and controls, power analysis, knowledge sharing and transmission, informal communication and coordination.

\section{Acknowledgements}

The study was supported by National Natural Science Foundation of China (Grant Nos. 70902045 and 70972071), Ministry of Education for Humanities and Social Sciences project (No. 09YJAZH067) and Program for Young Excellent Talents in Tongji University (2009KJ059). The authors also appreciate valuable comments from three anonymous reviewers.

\section{References}

Arnaboldi M., Azzone G. and Savoldelli A. (2004) Managing a public sector project: the case of the Italian Treasury Ministry. International fournal of Project Management, 22, 213-23.

Blackburn S. (2002) The project manager and the projectnetwork. International fournal of Project Management, 20, 199-204.

Borgatti S.P. and Foster P.C. (2003) The network paradigm in organizational research: a review and typology. fournal of Management, 29, 991.

Burt R.S. (1982) Toward a structural theory of action: network models of social structure, Academic Press: New York.

Bushe G.R. (1998) Power and the empowered organization: the design of power in highly adaptive organizations. Organization Development Practitioner, 30, 31-43.

Carless S.A. and De Paola C. (2000) The measurement of cohesion in work teams. Small Group Research, 31, 71.

Carron A.V. and Hausenblas H.A. (1998) Group Dynamics in Sport, 2nd Edn. Fitness Information Technology, Morgantown, WV.

Chinowsky P., Diekmann J. and Galotti V. (2008) Social network model of construction. Fournal of Construction Engineering and Management, 134, 804. 
Chinowsky P.S., Diekmann J. and O'Brien J. (2010) Project organizations as social networks. Fournal of Construction Engineering and Management, 136, 452.

Cooke-Davies, T., Cicmil, S., Crawford, L. and Richardson, K. (2007) We're not in Kansas anymore, Toto: mapping the strange landscape of complexity theory, and its relationship to project management. Project Management fournal, 38 (2), 50-61.

Diallo A. and Thuillier D. (2005) The success of international development projects, trust and communication: an African perspective. International fournal of Project Management, 23, 237-52.

Ellmann S. (2008) Management of complex projects: invisible structures, coordination and recommendations for management. Proceedings of the 22nd IPMA World Congress, Rome, Italy, 9-11 November 2008, pp. 12-32.

Etzioni A. (1975) A Comparative Analysis of Complex Organizations: On Power, Involvement, and Their Correlates, The Free Press of Glencoe, New York.

Flamholtz E. (1996) Effective organizational control: a framework, applications, and implications. European Management fournal, 14, 596-611.

Flamholtz E.G., Das T. and Tsui A.S. (1985) Toward an integrative framework of organizational control. Accounting. Organizations and Society, 10, 35-50.

Flyvbjerg B., Bruzelius N. and Rothengatter W. (2003) Megaprojects and Risk: An Anatomy of Ambition, Cambridge University Press, Cambridge.

Gray R.J. (2001) Organisational climate and project success. International fournal of Project Management, 19, 103-9.

Hanneman R.A. and Riddle M. (2005) Introduction to Social Network Methods, University of California-Riverside.

Hersey P., Blanchard K.H. and Johnson D.E. (1988) Management of Organizational Behavior, Prentice-Hall, Englewood Cliffs, NJ.

Hossain L. (2009) Effect of organisational position and network centrality on project coordination. International Fournal of Project Management, 27, 680-89.

Hossain L. and Wu A. (2009) Communications network centrality correlates to organisational coordination. International fournal of Project Management, 27, 795-811.

Ibarra H. (1993) Network centrality, power, and innovation involvement: determinants of technical and administrative roles. The Academy of Management Fournal, 36, 471-501.

Jaworski B.J. (1988) Toward a theory of marketing control: environmental context, control types, and consequences. The fournal of Marketing, 52, 23-39.

Karlsson H. and Lukka K. (2010) The existence and role of formal and informal feedback in organizational control. Working paper, Turku School of Economics, University of Turku, Finland.

Koerner M. and Klein L. (2008) Projects as differencetowards a next practice of complex project management. Proceedings Vol. 1.22 and IPMA World Congress, Rome, Italy, 9-11 November 2008, 158-63.

KPMG. (2005) Information risk management: global IT project management survey-how committed are you?
Krackhardt D. and Hanson J.R. (1993) Informal networks: the company behind the charts. Harvard Business Review, 71, 104-11.

Li Y. and Lu Y. (2009) Social network model of complex projects organization, International Conference on Management and Service Science. EEE, Wuhan, pp. 1-6.

Liu J. (2009) Lectures on Whole Network Approach: A practical guide to UCINET. Century Press Group, Shanghai, China.

Lukes S. (1981) Power: A Radical View, 2nd edn, Palgrave Macmillan, New York.

Luo J. (2005) Social Network Analysis, Social Sciences Academic Press, Beijing, China.

Mäkilouko M. (2004) Coping with multicultural projects: the leadership styles of Finnish project managers. International Fournal of Project Management, 22, 387-96.

Monge P.R. and Eisenberg E.M. (1987) Emergent communication networks, in Jablin F.M., Putnam L.L., Roberts K. H. and Porter L.W. (eds) Handbook of Organizational Communication, Sage, Newbury Park, CA.

Nieminen A. and Lehtonen M. (2008) Organisational control in programme teams: an empirical study in change programme context. International fournal of Project Management, 26, 63-72.

Ouchi W.G. (1979) A conceptual framework for the design of organizational control mechanisms. Management Science, 25, 833-48.

Pekericli M.K., Akinci B. and Karaesmen I. (2003) Modeling information dependencies in construction project network organizations. Proceedings of the Fourth foint International Symposium on Information Technology in civil Engineering, Nashville, TN, USA, 15-16 November 2003, 1-13.

Pettigrew A.M. (1973) The Politics of Organizational DecisionMaking, HarperCollins, New York.

PIPC. (2005). Global project management survey, Available at http://www.pmportal.co.uk/uploads/documents/ PIPCSurvey.pdf (accessed 18 July 2011).

Pryke S.D. (2004) Analysing construction project coalitions: exploring the application of social network analysis. Construction Management and Economics, 22, 787-97.

Pryke S.D. (2005) Towards a social network theory of project governance. Construction Management and Economics, 23, 927-39.

Schneider A. (1995) Project management in international teams: instruments for improving cooperation. International Fournal of Project Management, 13, 247-51.

Seeck H. and Kantola A. (2009) Organizational control: restrictive or productive? fournal of Management and Organization, 15, 241-57.

Simons R. (1994) How new top managers use control systems as levers of strategic renewal. Strategic Management fournal, $15,169-89$.

Singh A. and Eng P. (2009) Organizational power in perspective. Leadership and Management in Engineering, 9, 165.

Sullivan P.J. and Feltz D.L. (2001) The relationship between intrateam conflict and cohesion within hockey teams. Small Group Research, 32, 342.

Tan W. and Chong E. (2003) Power distance in Singapore construction organizations: implications for project 
managers. International fournal of Project Management, 21, 529-36.

Toffler A. and Butz B. (1990) Powershift: Knowledge, Wealth, and Violence at the Edge of the 21st Century, Bantam Books, New York.

Van Donk D.P. and Molloy E. (2008) From organising as projects to projects as organisations. International fournal of Project Management, 26, 129-37.

Wasserman S. and Faust K. (1995) Social Network Analysis: Methods and Applications, Cambridge University Press, Cambridge.
Whittaker B. (1999) What went wrong? Unsuccessful information technology projects. Information Management and Computer Security, 7, 23-30.

Winter M., Smith C., Morris P. and Cicmil S. (2006) Directions for future research in project management: the main findings of a UK government-funded research network. International fournal of Project Management, 24, 638-49.

Zemljic B. and Hlebec V. (2005) Reliability of measures of centrality and prominence. Social Networks, 27, $73-88$. 


\section{Appendix 1}

Table A1 Abbreviations used in the SNA model and result

\section{1. $\mathrm{CHO}$ \\ 1Q01 Director \\ 1Q02 Deputy Director 1 \\ 1Q03 Deputy Director 1 \\ 1Q04 Manager of Technics \\ 1Q05 Manager of Engineering \\ 1Q06 Administrative Manager \\ 1Q07 Manager of Contract and Finance \\ 1Q08 Deputy Manager of Facilities}

2. Pavilions and temporary facilities in Pudong area

2D01 Shanghai Institute of Architectural Design and Research Company

2C01 Shanghai Construction Group

2C02 Shanghai No. 5 Construction Company

2A01 Shanghai Project Management Company

2C03 Shanghai Baoye Group Corporation

2A02 Shanghai Jianke Project Management Company

3. EXPO axis

3F01 Shanghai Mitsubishi Elevator

3F02 Schindler China

4. China pavilion

4D01 Institute of Architectural Design and Research Company, South China University of Technology

4D02 Beijing TinghuaAndi Architectural Design Consulting Company

5. Roads and municipal projects in Pudong area

5C01 Shanghai Gardens Group

5C02 Shanghai No. 5 Construction Company

5A01 Shanghai Construction Engineering Administration Company

5C03 Shanghai No. 2 Municipal Engineering Company

5C04 Shanghai No. 7 Construction Company

5A02 Shanghai Municipal Gongcheng Management Consultation Company

5A03 Shanghai Simeikehui Construction Engineering Consultation Company
1Q09 Deputy manager of equipment

1Q10 Deputy manager of safety and quality

1Q11 Manager of coordination

1Q12 Project manager for sections A and B

1Q13 Project manager for section C

1Q14 Project manager for China pavilion

1Q15 Project manager for EXPO axis

1Q16 Project manager for municipal facilities in Pudong area

2C04 China Construction Eighth Engineering Division

2A03 Shanghai Kerui Construction Project Management Company

2C05 HONGRUN Construction Group

2A05 Tongji University

2A06 Shanghai Shangzi Construction Budget Consulting Company

3D01 SBA Gmbh (Germany), China

3A01 Shanghai Oriental Investment Supervision Company

4C01 Shanghai Mechanized Construction Corporation

4C02 Shanghai Installation Engineering Company

5D01 Shanghai Municipal Engineering Design General Institute

5D02 Shanghai Urban Planning and Design Research Institute

5A04 Shanghai Cai Rui Construction Consulting Company

5C05 Shanghai Yuandong International Qianliang Jianshe Company

5A05 Shanghai Zhuyuan Project Management

5A06 Shanghai Tianyou Engineering Consulting Company

5C06 Shanghai No. 4 Construction Company

Note: $\mathrm{Q}$ is $\mathrm{CHO}, \mathrm{A}$ is project management firms or quality and safety supervision firms, $\mathrm{C}$ is contractors and $\mathrm{D}$ is design firms. 